\title{
Microbial loop processes shape the food web stoichiometry in Lake Kinneret
}

\author{
$\underline{\text { Y. Li }}{ }^{\text {a,b }}$, G. Gal $^{\text {c }}$, A.M. Waite ${ }^{\text {d }}$ and M.R. Hipsey ${ }^{a}$ \\ ${ }^{a}$ School of Earth and Environment, The University of Western Australia, Crawley WA 6009, Australia. \\ Email: liy15@student.uwa.edu.au \\ ${ }^{b}$ School of Environmental Science \& Engineering, Ocean University of China, Qingdao 266100, China. \\ ${ }^{c}$ Israel Oceanographic and Limnological Research, Migdal 14950, Israel. \\ ${ }^{d}$ The Oceans Institute, The University of Western Australia, Crawley WA 6009, Australia.
}

\begin{abstract}
Nutrient cycling in the pelagic zone of aquatic ecosystems is generally controlled by the interactions between zooplankton, phytoplankton and bacteria. However, very little is known about how microbial interactions influence the stoichiometry of trophic levels within freshwater ecosystems. In order to better understand these interactions, we examined how the microbial loop shaped the N:P stoichiometry of food web components in Lake Kinneret. We used two microbial loop sub-models incorporated into a onedimensional coupled hydrodynamic-ecological model (DYRESM-CAEDYM) to simulate the effect of microbial loop processes on the N:P stoichiometry of the food web. The stoichiometry of nutrient recycling pathways illustrated that the ability of bacteria to regulate phytoplankton stoichiometry is a significant factor that has ecosystem wide implications. The results showed that the average internal $\mathrm{N}: \mathrm{P}$ ratios of the combined phytoplankton community followed their $\mathrm{C}$ biomass patterns. However, variations in the internal $\mathrm{N}: \mathrm{P}$ ratios of the five simulated phytoplankton species occurred depending on the operation of the microbial loop, suggesting that predicting the N:P ratios of the nutrient flux pathways between bacteria, zooplankton and inorganic matter are important in correctly predicting the available nutrients for individual phytoplankton groups, and their overall patterns of growth. The dynamic shifts in nutrient stoichiometry induced by changes in the microbial loop within Lake Kinneret provide an improved mechanistic understanding of microbial interactions in aquatic ecosystems.
\end{abstract}

Keywords: Microbial loop, food web stoichiometry, Lake Kinneret, DYRESM-CAEDYM 


\section{INTRODUCTION}

Aquatic ecosystems play an important role in supporting economic, recreational and environmental aspects of a sustainable society. However, with increasing human activities, large quantities of nutrients have been mobilized into water bodies, which frequently results in algal blooms and the associated deterioration of water quality. While nutrients are a key driver in algal blooms, these blooms are also known to be mediated by microbial interactions. However, less is known about how the interactions between zooplankton, phytoplankton and bacteria influence nutrient flows between trophic levels, and how these may support or hinder algal blooms.

Traditionally, studies of aquatic ecosystems have assumed the classic 'nutrients-phytoplankton-zooplankton' paradigm. However, it is now well accepted that predators such as crustacean zooplankton or fish can also be supported by the detrital-based component of aquatic ecosystems, also known as the 'microbial loop' (Azam et al., 1983; Moore et al., 2004). Pomeroy et al. (2007) described the microbial loop as 'functionally intertwined' with plants, herbivores, and carnivores, and suggested the loop channels energy and carbon from bacteria to microzooplankton, and ultimately to larger zooplankton and fish. In order to better understand the impact of microbial loop processes on nutrient recycling and phytoplankton growth, we need to understand the interactions between zooplankton, phytoplankton and bacteria. These may influence the ecological stoichiometry at different trophic levels.

Microbes in the water column influence the overall patterns of stoichiometry at different trophic levels by their interactions. Heterotrophic and autotrophic microorganisms regulate $\mathrm{C}: \mathrm{N}: \mathrm{P}$ ratios in aquatic ecosystems by coupling carbon-to-nutrient recycling processes (Thingstad et al., 2008). As the size range of heterotrophic flagellates and microzooplankton are the same as phytoplankton, they facilitate the movement of energy, carbon and nutrients from the microbial loop to the conventional food chain (Azam et al., 1983; Stone et al., 1993; Hart et al., 2000; Hambright et al., 2007). The physiological constraints of a constant N:P ratio in bacteria has been shown to regulate the flow of nutrients to phytoplankton in experimental cultures (Danger et al., 2007).

Ecological stoichiometry principles have emerged as an established method to study the pelagic and benthic zones of freshwater systems (Cross et al., 2005), stoichiometric variation of phytoplankton holds the key to the study of the food web (Sterner and Elser, 2002). In this study, we merge the use of a lake ecosystem model and ecological stoichiometry principles to:

- $\quad$ investigate how trophic levels and interactions are organized from a stoichiometric perspective;

- examine the significance of the microbial loop in shaping N:P stoichiometry of the food web, especially phytoplankton;

- explore how the microbial loop regulates the stoichiometry of nutrient flows in Lake Kinneret (Israel).

\section{METHOD}

\subsection{Site Description}

Lake Kinneret (Sea of Galilee) is a large mesotrophic lake located in north-eastern Israel, which covers an area of $170 \mathrm{~km}^{2}$. The length of the lake is $21 \mathrm{~km}$, the width is $16 \mathrm{~km}$, and the mean and maximum depths are $26 \mathrm{~m}$ and $43 \mathrm{~m}$, respectively. The lake is of critical importance to Israel since it supplies about the half of the country's drinking water. The deterioration of water quality in Lake Kinneret has been the focus of considerable limnological research over the past few decades (for example, see Berman et al., 1995; Zohary, 2004; Roelke et al., 2007; Gal et al., 2009). In particular, the lake is well known for the once regular occurrences of the dinoflagellate Peridinium gatunese (Zohary et al., 1998). Recently, its historically stable phytoplankton assemblage was observed to be disrupted and frequent occurrences of nuisance cyanobacterial species have become a concern (Zohary, 2004).

\subsection{Model Overview}

The coupled Dynamic Reservoir Simulation Model (DYRESM)-Computational Aquatic Ecosystem Dynamics Model (CAEDYM) was run against the field data from 1997-2001. Parameters for running DYRESM-CAEDYM in Lake Kinneret were adopted from the previous work on the lake and the model validation has reasonably captured the main seasonal patterns of biogeochemical and ecological interactions 
(Gal et al., 2009; Li et al., manuscript in preparation). The following two configurations have been used here to test the impact of the microbial loop on the ecosystem trophic structure in the lake (Figure 1):

(1) Microbial Loop Absent Configuration (MLAC): This simulation assumed organic matter was mineralized at a rate that was not dependent on the bacterial biomass. This approach fluxed $\mathrm{C}, \mathrm{N}$ and $\mathrm{P}$ between DOM and DIM proportionally. The microzooplankton consumed DPOM instead of bacteria as they were assumed to be lumped together.

(2) Microbial Loop Present Configuration (MLPC): This simulation assumed organic matter was mineralized by a simulated bacteria group. Moreover, bacteria could supplement their internal nutrient requirement during growth by taking inorganic nutrients, and in doing so, compete with phytoplankton for nutrients.

\subsection{Calculation of Stoichiometric Ratios}

The nutrient pools and fluxes were averaged over the simulation time period (1997-2001). Nutrient variables and biological variables listed in Figure 1 were integrated in the whole lake to calculate

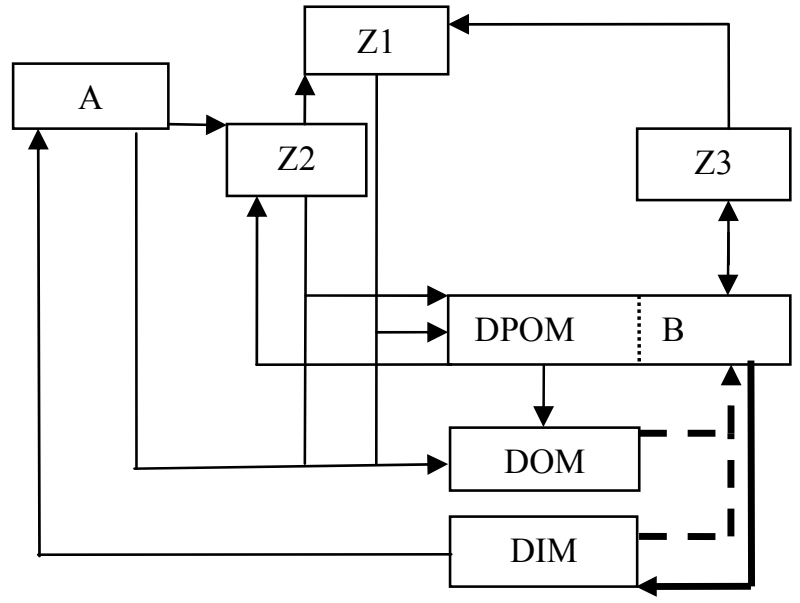

Figure 1. Conceptual diagram highlighting feedbacks for microbial interactions in Lake Kinneret (A: phytoplankton, including five species (A1-A5); B: bacteria; DOM: dissolved organic matter; DIM: dissolved inorganic matter; DPOM: detritus particular organic matter; Z1: predatory zooplankton; Z2: herbivorous zooplankton; Z3: microzooplankton ). Solid lines indicate the common processes of MLAC and MLPC. Dashed lines indicate bacterial uptake DOM and DIM in MLPC.

their averages over time, and the average pools and fluxes of $\mathrm{N}$ and $\mathrm{P}$ were converted to molar ratios. The internal N:P ratios (IN:IP ratios) for the biological state variables were organized into three different groups: fixed stoichiometry (bacteria and zooplankton), variable stoichiometry within a user defined range (phytoplankton) and free-to-change stoichiometry according to microbial interactions (POM, DOM, and DIM). The ratios of nutrient fluxes were calculated based on the integration of the relevant process variables.

\section{RESULTS}

\subsection{Model Performance}

The simulated physical and chemical variables, such as lake level, thermal structure, DO, TN, TP, $\mathrm{NO}_{3}, \mathrm{NH}_{4}$, matched well the seasonal patterns and nutrient dynamics of the lake observations (Gal et al., 2009; Li et al., manuscript in preparation). Though some discrepancies existed in biological variables, e.g. the inter-annual variation in algal bloom size, they were generally well predicted and the biological outputs in MLPC provided a closer match to the observations compared to MLAC.

\subsection{Averaged Food Web N:P Stoichiometry}

In MLAC and MLPC, the stoichiometry of zooplankton were fixed, and their IN:IP ratios were 27:1 (predatory zooplankton), 20:1 (herbivorous zooplankton), and 28:1 (microzooplankton). The IN:IP ratios of phytoplankton were variable due to the kinetic uptake algorithms in the model. The ratios of nutrient pools were also free to change. In MLAC (Figure 2a), the N:P ratios of the DOM and DIM pools were 307:1 and $109: 1$, respectively. While the stoichiometry of the five simulated phytoplankton groups varied over the course of the simulation, their averages over the simulation period were 150:1 (Peridinium), 9:1 (Microcystis), 3:1 (Aphanizomenon), 55:1 (nano-phytoplankton), and 15:1 (Aulacoseira). In contrast with MLAC, the IN:IP ratios of phytoplankton changed in the MPLC simulation (Figure $2 \mathrm{~b}$ ). The major change was Peridinium from 150:1 to 107:1 and the others species had only minor changes (Microcystis from 9:1 to 8:1; Aphanizomenon from 3:1 to 4:1; nano-phytoplankton from 55:1 to 47:1; Aulacoseira from 15:1 to 16:1). The IN:IP ratios of Peridinium, Microcystis, and nano-phytoplankton decreased, whereas the IN:IP ratios of Aphanizomenon and Aulacoseira increased slightly. In the water column, the N:P ratios of the DOM pool increased dramatically from 307:1 to $3543: 1$, but the N:P ratio of the DIM pool decreased from 109:1 to 67:1. These changes were more significant than the changes in phytoplankton. 
The differences in N:P stoichiometry of the different pools resulted in different N:P ratios of the nutrient flux pathways in the water column. In MLAC, for internal transformations, the N:P ratio of algal nutrient uptake was $31: 1$, and the N:P ratio of algal excretion was 35:1. When bacteria competed with phytoplankton for DIM in MPLC, the N:P ratios of algal nutrient uptake and algal excretion decreased to 22:1 and 20:1 respectively. Correspondingly, the N:P ratio of zooplankton excretion decreased from 72:1 in MLAC to 13:1 in MLPC. Because the N:P ratios of bacterial DOM uptake, the remineralization rate, and bacterial grazing rate were all 5:1, bacteria were nutrient-balanced. For external forcing, the N:P ratio of the sediment release rate was stable (33:1). Inflow and outflow hydrodynamics were negligible as they contributed a small percentage to the overall processes.

\section{Heterotrophic}

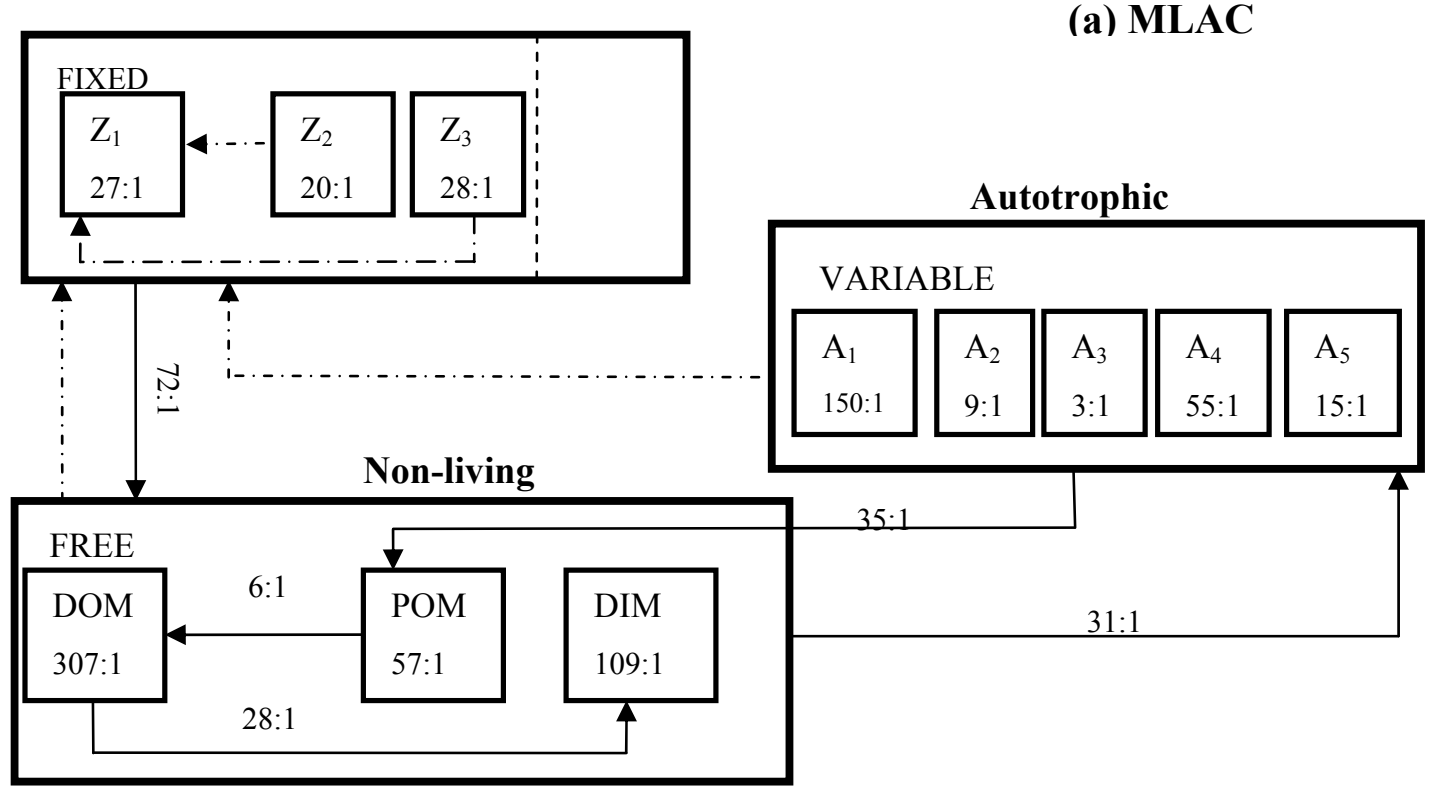

\section{Heterotrophic}

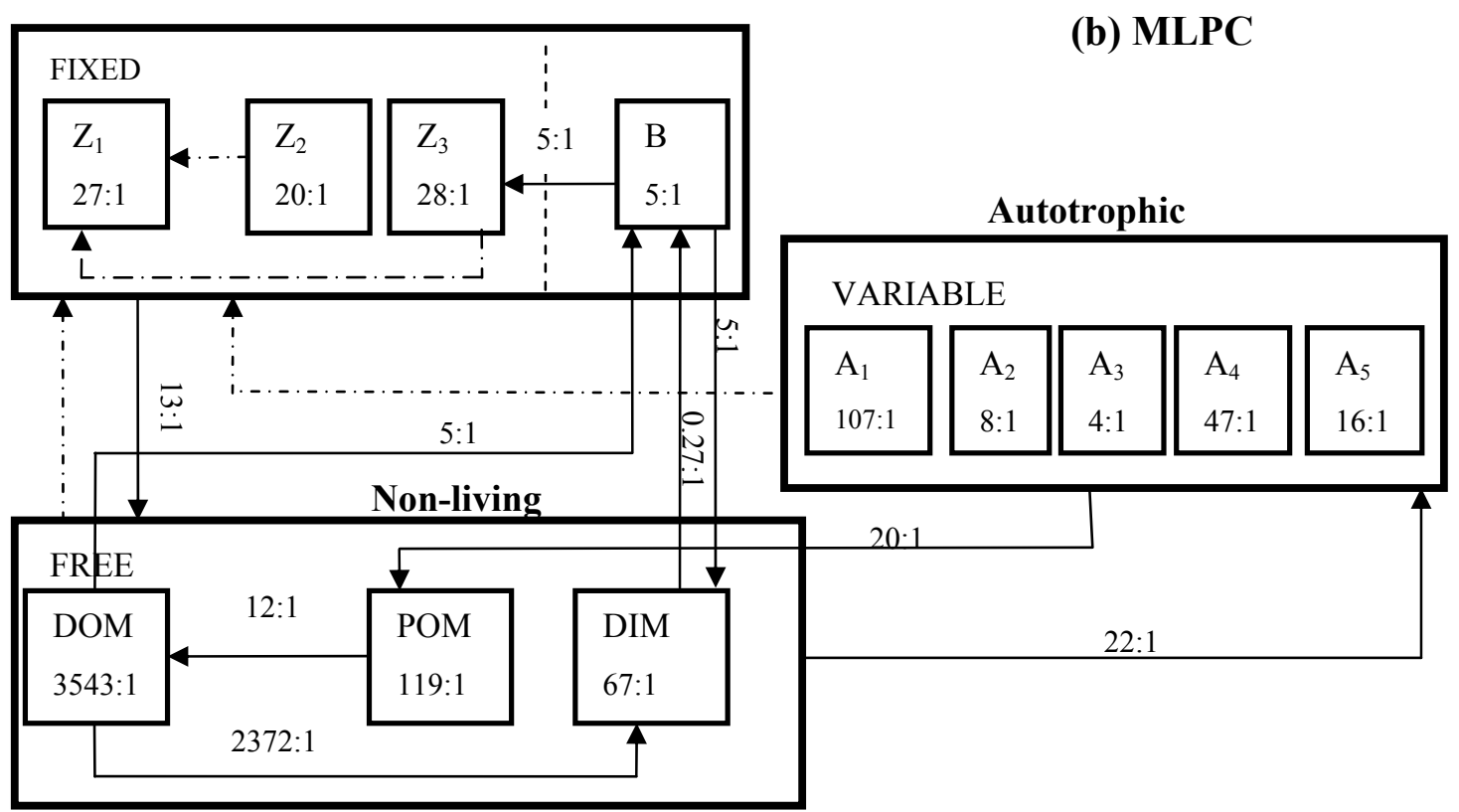

Figure 2. Average predicted N:P ratios of the food web components and flux pathways in the (a) MLAC and (b) MLPC simulations. 


\subsection{N:P Stoichiometry of the Phytoplankton Community}

The microbial loop had a significant effect on the average predicted IN:IP ratios of individual phytoplankton species (Figure 2). The overall IN:IP ratio pattern of the combined phytoplankton community is however also of interest. The predicted seasonal $\mathrm{C}$ biomass patterns of the combined phytoplankton community matched their predicted IN:IP ratio patterns well (Figure 3). While these two patterns were similar, the C biomass peaks slightly lagged behind the IN:IP ratio peaks. Furthermore, the magnitude of the $\mathrm{C}$ biomass peaks of the combined phytoplankton community compared reasonably well with the magnitude of the changes in the predicted IN:IP ratios.

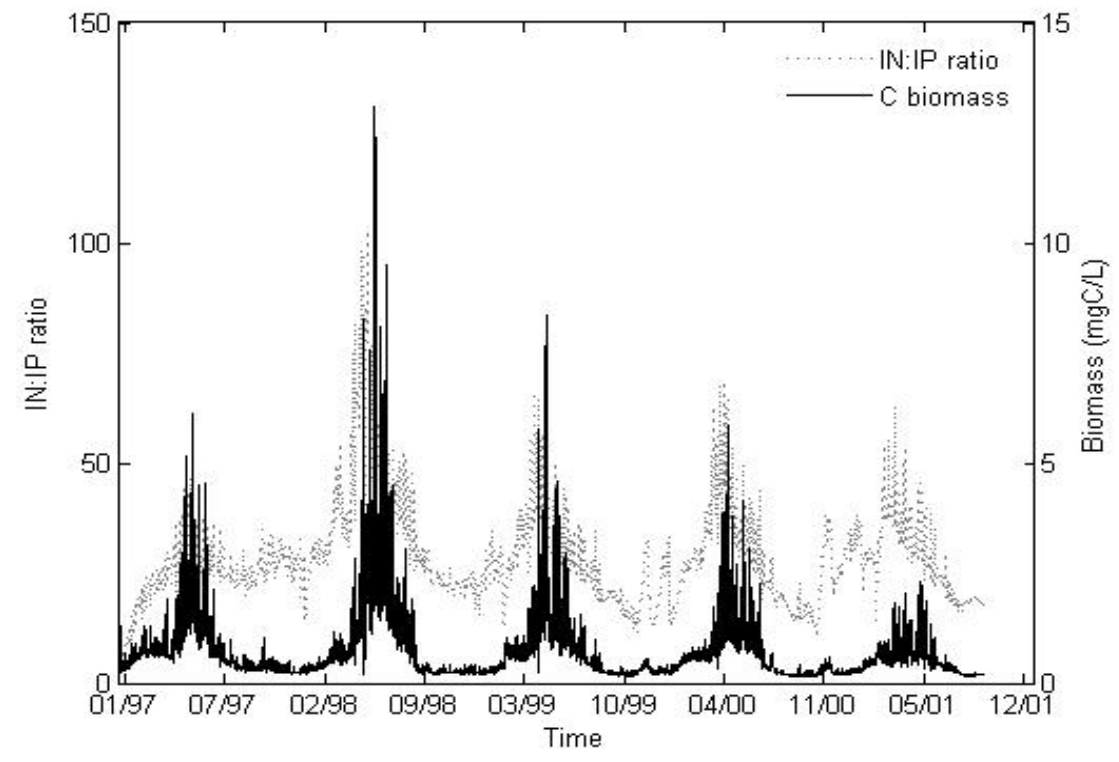

Figure 3. The predicted IN:IP molar ratios vs. C biomass of phytoplankton during the simulation period.

\section{DISCUSSION}

\subsection{N:P Stoichiometry of the Microbial Loop}

In our two sub-models, the stoichiometry of zooplankton was fixed because zooplankton have fairly constant internal N:P ratios (Sterner and Elser, 2002), although some variability has been reported in Lake Kinneret (Rachamim et al., 2010). In addition, the presence of the microbial loop affects the zooplankton community structure (Peduzzi et al., 1992). But for the purposes of this study the constancy of zooplankton stoichiometry in our model demonstrates the potential for stoichiometric regulation of nutrient flows.

Similarly, as bacteria are more like animals than plants in terms of N:P homeostasis (Makino et al., 2003), their stoichiometric regulation affects the N:P ratios of the excreted nutrient fluxes, and hence the available nutrients for phytoplankton. In the microbial loop, bacteria are a nutrient-rich source of food consumed by the microzooplankton and the consumption of bacteria by microzooplankton leads to an input of nutrient stoichiometry in excess of what is required. This ultimately results in an enhancement of the nutrient excretion by zooplankton to the food web. When the N:P ratio imbalance occurs within the food web, $\mathrm{C}$ may be accumulated in the organic matter pool (Frost et al., 2002). Moreover, P-deplete organic compounds also accumulate as the N:P ratio of DOM in the presence of microbial loop configuration increased by an order of magnitude compared to the absence of microbial loop configuration. In this case, the organic compounds induce P-limitation in the bacterial growth, as observed by Caron (1994), which further propogates through the food web to make DOP mineralisation the limiting factor for phytoplankton growth (Li et al., manuscript in preparation). Therefore, the microbial loop influences $\mathrm{P}$ recycling more strongly than $\mathrm{N}$ recycling in Lake Kinneret. 


\subsection{N:P Stoichiometry of the Phytoplankton}

Through comparison of the different simulation results, the stoichiometry of nutrient recycling pathways illustrates the ability of bacteria to regulate phytoplankton stoichiometry and this has ecosystem wide implications. Bacteria can switch the nutrient limitation of phytoplankton growth and change their population structure (Danger et al., 2007; Li et al., manuscript in preparation). Similarly, our results show that the microbial loop may further restructure the bulk IN:IP ratios of the phytoplankton community since phytoplankton growth becomes nutrient limited at different levels when bacteria regulate nutrient recycling processes. This restructuring is demonstrated through modest changes to phytoplankton, which are able to control their stoichiometry to a certain degree, compared to significant changes in the DIM/DOM/DPOM pools. The most significant change in the phytoplankton community is Peridinium, because different specific growth rates of phytoflagellate results in their different IN:IP ratios (Sterner and Elser, 2002).

As Lake Kinneret is P-limited, the IN:IP ratios of the individual phytoplankton species vary because of the optimal allocation strategy in two phytoplankton cellular machineries (Klausmeiser et al., 2004). As exponential growth and competitive equilibrium represent two different growth phases of phytoplankton, the competitive equilibrium preference of Peridinium and nano-phytoplankton facilitates P-poor resourceacquisition machinery to develop their higher IN:IP ratios; the exponential growth of cyanobacteria favors Prich assembly machinery to develop the lower N:P ratios of Microcystis and Aphanizomenon. The average IN:IP ratio of Aulacoseira closely matches the Redfield ratio regardless of the overall nutrient limitation.

The IN:IP ratio patterns of the whole phytoplankton community reflect their $\mathrm{C}$ biomass patterns, although the microbial loop processes affect the elemental composition of phytoplankton communities. The $\mathrm{C}$ biomass patterns of the combined phytoplankton community followed their IN:IP ratio patterns with a small time lag. Furthermore, the magnitude of the seasonal shift in algal $\mathrm{C}$ biomass followed the magnitude of the shift in their IN:IP ratios. Currently, the abundance of phytoplankton in lake ecosystem models, such as DYRESMCAEDYM, is usually represented by $\mathrm{C}$ biomass or Chl-a, and the internal $\mathrm{N}$ and $\mathrm{P}$ content of phytoplankton are seldom measured. The model shows the correlation between the algal $\mathrm{C}$ biomass and internal N:P ratios, which can help build our understanding of the correlation between different forms of N:P ratios in the water column and algal biomass. Until now there have been many types of N:P ratios for discriminating nutrient limitation of phytoplankton growth, such as inorganic N:P ratios (Deutsch et al., 2007; Ballantyne et al., 2010), total N:P ratios (Hall et al., 2005), and dissolved inorganic N:total P (DIN:TP) ratios (Morris et al., 1988; Li et al., 2011). In the future, different types of N:P ratios should be compared to select the most appropriate for further exploring the usefulness of these $\mathrm{N}: \mathrm{P}$ ratios in determining the relationship between phytoplankton IN:IP ratios and water column N:P ratios in a dynamic aquatic environment.

\section{ACKNOWLEDGMENTS}

We thank the Kinneret Limnological Laboratory (KLL) for making the field data available to us. Funding for travel to visit Lake Kinneret for GLEON12 was provided by the National Science Foundation Cyber-enabled and Innovation (CDI) Program, Award \#941510. Funding for Y. Li's PhD study at the University of Western Australia is provided by the China Scholarship Council (CSC).

\section{REFERENCES}

Azam, F., Fenchel, T., Field, J., Gray, J.S., Meyer-Reil, L. A., Thingstad, F. (1983). The Ecological Role of Water-Column Microbes in the Sea. Marine Ecology Progress Series, 10:257-263.

Ballantyne IV, F., Menge, D. N. L., Weitz, J. S. (2010). A discrepancy between predictions of saturating nutrient uptake models and nitrogen-to-phosphorus stoichiometry in the surface ocean. Limnology and Oceanography, 55, 997-1008.

Berman, T., Stone, L., Yacobi, Y.Z., Kaplan, B., Schlichter, M., Nishri, A., Pollingher, U. (1995). Primary production and phytoplankton in Lake Kinneret: a long-term record (1972-1993). Limnology and Oceanography, 40: 1064-1076.

Caron, D.A. Inorganic nutrients, bacteria, and the microbial loop. Microbial Ecology, 28: 295-298.

Cross, W.F., Benstead, J.P., Frost, P.C., Thomas, S.A. (2005). Ecological stoichiometry in freshwater benthic systems: recent progress and perspectives. Freshwater Biology, 50: 1895-1912.

Danger, M., Oumarou, C., Benest, D., Lacroix, G. (2007). Bacteria can control stoichiometry and nutrient limitation of phytoplankton. Functional Ecology, 21: 202-210.

Deutsch, C., Sarmiento, J.L., Sigman, D.M., Gruber, N., Donne, J.P.(2007). Spatial coupling of nitrogen inputs and losses in the ocean. Nature, 445: 163-167. 
Frost, P.C., Stelzer, R.S., Lamberti, G.A, Elser, J.J. (2002). Ecological Stoichiometry of Trophic Interactions in the Benthos: Understanding the Role of C:N:P Ratios in Lentic and Lotic Habitats. Journal of the North American Benthological Society, 21: 515-528.

Gal, G., Imberger, J., Zohary, T., Antenucci, J.P., Anis, A., Rosenberg, T. (2003). Simulating the thermal dynamics of Lake Kinneret. Ecological Modelling, 162: 69-86.

Gal, G., Hipsey, M.R., Parparov, A., Wagner, U., Makler, V., Zohary, T. (2009). Implementation of ecological modeling as an effective management and investigation tool: Lake Kinneret as a case study. Ecological Modelling, 220:1697-1718.

Hall, S.R., Smith, V.H., Lytle, D.A., Leibold, M.A. (2005). Constraints on primary producer N:P stoichiometry along N:P supply ratio gradients. Ecology, 86: 1894-1904.

Hambright, K.D., Zohary, T., Gude, H. (2007). Microzooplankton dominate carbon flow and nutrient cycling in a warm subtropical freshwater lake. Limnology and Oceanography, 52: 1018-1025.

Hart, D.R., Stone, L., Berman, T. (2000). Seasonal dynamics of the Lake Kinneret food web: The importance of the microbial loop. Limnology and Oceanography, 45: 350-361.

Klausmeiser, C.A., Litchman, E., Daufresne, T., Levin, S.A. (2004). Optimal nitrogen-to-phosphorus stoichiometry of phytoplankton. Nature, 429: 171-174.

Li, Y., Hipsey, M.R., Waite, A., Makler-Pick, V., Gal, G. Significance of the microbial loop in regulating phytoplankton succession: Numerical investigation of Lake Kinneret (Israel). In draft.

Li, Y., Waite, A.M., Gal, G., Hipsey M.R., (2011). Do phytoplankton nutrient ratios reflect patterns of water column nutrient ratios? A numerical stoichiometric analysis of Lake Kinneret. Procedia Environmental Sciences (ISEM2011), Beijing, China.

Makino, W., Cotner, J.B., Sterner, R.W., Elser, J.J. (2003). Are bacteria more like plants or animals? Growth rate and resource dependence of bacterial C: N: P stoichiometry. Functional Ecology, 17: 121-130.

Morris, D.P., Lewis, W.M. (1988). Phytoplankton nutrient limitation in Colorado mountain lakes. Freshwater

Biology, 20:315-27.

Moore, J.C., Berlow, E.L., Coleman, D.C., Ruiter, P.C., Dong, Q., Hastings, A., Johnson, N.C., McCann, K.S., Melville, K., Morin, P.J., Nadelhoffer, K., Rosemond, A. D., Post, D.M., Sabo, J.L., Scow, K.M., Vanni, M. J., Wall, D. H. (2004). Detritus, trophic dynamics and biodiversity. Ecological Letters, 7: 584600.

Peduzzi, P., Herndl, G.J. (1992). Zooplankton activity fueling the microbial loop: Differential growth response of bacteria from oligotrophic and eutrophic waters. Limnology and Oceanography, 37:10871092.

Pomeroy, L.R., Leb, P.J., Azam, W.F., Hobbie, J.E. (2007). The Microbial Loop. Oceanography, 20: 28-33.

Rachamim, T., Stambler, N., Zohary, T., Berman-Frank, I., Gal, G.(2010). Zooplankton contribution to the particulate $\mathrm{N}$ and $\mathrm{P}$ in Lake Kinneret, Israel, under changing water levels. Hydrobiologia, 655:121-135.

Roelke, D.L., Zohary, T., Hambright, K.D., Montoya, J.V. (2007). Alternative states in the phytoplankton of Lake Kinneret, Israel (Sea of Galilee). Freshwater Biology, 52:399-411.

Sterner, R.W., Elser, J.J. (2002). Ecological Stoichiometry: The Biology of Elements from Molecules to the Biosphere. Princeton University Press, New Jersey.

Stone, L., Berman, T., Bonner, R., Barry, S., Weeks, S.W. (1993). Lake Kinneret: A seasonal model for carbon flux through the planktonic biota. Limnology and Oceanography, 38: 1680-1695.

Thingstad,T.F., Bellerby, R.G.J., Bratbak, G., Børsheim, K.Y., Egge1, J. K., Heldal, M., Larsen, A., Neil, C., Nejstgaard, J., Norland, S., Sandaa, R. A., Skjoldal, E. F., Tanaka, T., Thyrhaug, R., Töpper, B. (2008). Counterintuitive carbon-to-nutrient coupling in an Arctic pelagic ecosystem. Nature, 455: 387-390.

Zohary, T., Pollingher, U., Hadas, O., Hambright, K.D. (1998). Bloom dynamics and sedimentation of Peridinium gatunense in Lake Kinneret. Limnology and Oceanography, 43: 175-186.

Zohary, T. (2004). Changes to the phytoplankton assemblage of Lake Kinneret after decades of a predictable, repetitive pattern. Freshwater Biology, 49: 1355-1371. 